\title{
Anomalous Kinetics of Diffusion-Controlled Defect Annealing in Irradiated Ionic Solids
}

\author{
Eugene Kotomin, ${ }^{, \dagger, \dagger}$ Vladimir Kuzovkov ${ }^{\ddagger}$ Anatoli Popov, ${ }^{\ddagger}$ Joachim Maier, ${ }^{\dagger}$ and \\ Rafael Vila \\ $\dagger$ Max Planck Institute for Solid State Research, Stuttgart, Germany \\ $\ddagger$ Institute of Solid State Physics, University of Latvia, Riga, Latvia \\ ๑CIEMAT, Madrid, Spain \\ E-mail: E.Kotomin@fkf.mpg.de \\ Phone: +49 7116891769
}

\begin{abstract}
The annealing kinetics of the primary electronic $F$-type color centers (oxygen vacancies with trapped one or two electrons) is analysed for three ionic materials $\left(\mathrm{Al}_{2} \mathrm{O}_{3}, \mathrm{MgO}\right.$ and $\left.\mathrm{MgF}_{2}\right)$ exposed to intensive irradiation by electrons, neutrons and heavy swift ions. Phenomenological theory of diffusion- controlled recombination of the $F$-type centers with much more mobile interstitial ions (complementary hole centers) allows us to extract from experimental data the migration energy of interstitials and preexponential factor of diffusion. The obtained migration energies are compared with available first principles calculations. It is demonstrated that with the increase of radiation fluence, both the migration energy and pre-exponent are decreasing in all three materials, irrespective of the type of irradiation. Their correlation satisfies the Meyer-Neldel rule observed earlier in glasses, liquids, and disordered materials. The origin of this effect is discussed. This study demonstrates that in the quantitative analysis of the radiation damage of real materials, the dependence of the defect migration parameters on the radiation fluence plays an important role and cannot be neglected.
\end{abstract}

\section{Introduction}

Irradiation resistance is important material property, vital for many applications, including nuclear fuels, ${ }^{1}$ reactor materials, and nuclear waste storage. ${ }^{2,3} \mathrm{MgO}, \alpha-\mathrm{Al}_{2} \mathrm{O}_{3}$ (sapphire, corundum), and $\mathrm{MgF}_{2}$ are three wide gap insulating materials with different crystalline structures and chemical bonding. All three materials are radiation resistant and have many important applications, e.g. sapphire, is a promising material for fusion reactors, mainly for diagnostics as a general insulator or optical components, ${ }^{4}$ whereas optical lenses and devices from $\mathrm{MgF}_{2}$ are transparent in an extremely wide range of photon energies, from IR to UV. ${ }^{5}$ To control radiation stability, it is very important to predict/simulate the kinetics of defect accumulation and thus radiation damage in these materials as well as long-time defect structure evolution. ${ }^{6-11}$

There were numerous experimental measurements of the primary defect accumulation kinetics (first of all, $F$ - and $F^{+}$color centers - oxygen vacancy with two and one trapped electrons, respectively) as a function of radiation dose rate and temperature with subsequent post-irradiation annealing. ${ }^{12-14}$ Defect kinetics in solids are controlled by defect diffusion. Unlike liquids, where diffusion coefficients of particles and impurities are similar, ${ }^{15,16}$ in solids 
diffusion coefficients of different defects could vary by many orders of magnitude. ${ }^{6,13}$ As is well known, the $F$ center mobility is much smaller than that of the complementary Frenkel defects interstitial oxygen ions. ${ }^{17,18}$ Thus, at moderate radiation fluences and temperatures, the kinetics of the $F$-type center annealing is governed by their diffusion-controlled recombination with mobile oxygen interstitials. Despite numerous experimental data on defect kinetics, very few theoretical efforts were devoted so far to the quantitative analysis of available data, in order to extract main kinetic parameters - interstitial migration energy $E_{a}$ and diffusion pre-exponent $D_{0}$ - necessary for further prediction of the secondary defect kinetics and radiation stability of sapphire and related materials.

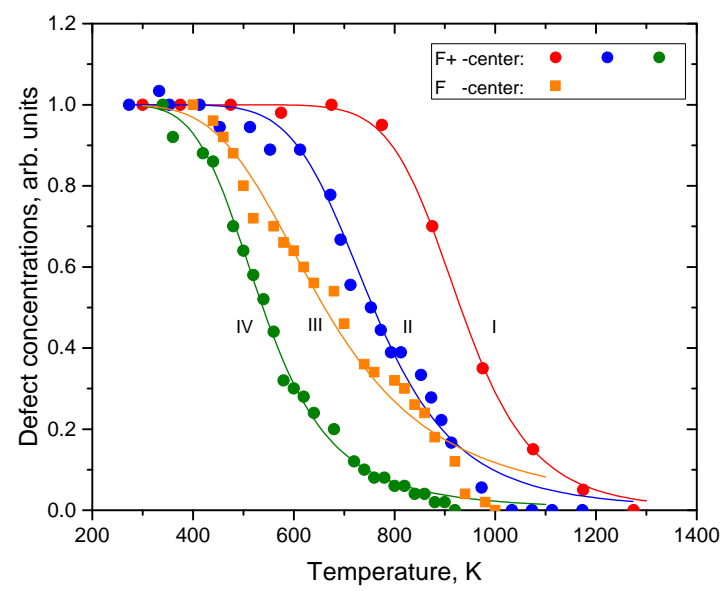

Figure 1: The kinetics of the $F$ or $F^{+}$center annealing in $\mathrm{Al}_{2} \mathrm{O}_{3}$ (see Table 1 for details, only four representative kinetics are plotted here for illustration).

Recently, a simple phenomenological theory of diffusion-controlled bimolecular recombination of Frenkel defects was developed and applied to irradiated ionic solids. ${ }^{19,20}$ We developed the alternative approach based on the formalism of joint correlation functions ${ }^{6,7}$ of spatial distribution of similar $(F-F$ centers $)$ and dissimilar (Frenkel pair of defects: the $F$ center - interstitial Oi ions) which is well suited for the study of radiation defect kinetics and aggregation.
The atomistic model of radiation damage takes into account the following steps: Frenkel defect production ( $F$ center - interstitial) (ii) Defect migration with the diffusion coefficient determined by the activation energy $E_{a}$ and pre-exponent $D_{0}$. (iii) Dissimilar defect recombination upon mutual approach within the critical radius $R$. (iv) Post-irradiation annealing with linear increase of temperature.

One could estimate the diffusion coefficients of defects in solids, from measurements of the defect concentration changes (by optical absorption and ESR) under different conditions, e.g. sample heating (annealing) which stimulates defect reactions and recombination. The reaction rate $K$ is related to a mutual diffusion coefficient $D$ via simple relation $K=4 \pi D R,{ }^{21}$ where $D=D_{0} \exp \left(-E_{a} / k_{B} T\right)$ and $R$ recombination radius. The non-isothermal kinetics (heating) ${ }^{19,20}$ is considered in this paper.

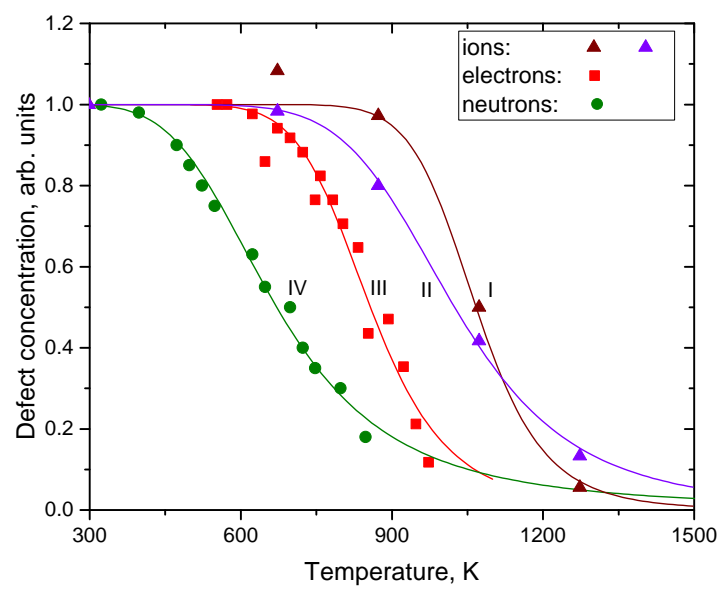

Figure 2: The kinetics of the $F^{+}$center annealing in $\mathrm{MgO}$ for different types of radiation (see Table 2 for details).

As it was shown therein, the kinetics of bimolecular recombination of the primary radiation defects $F$ type centers and interstitial ions - is controlled by the two parameters: the activation energy $E_{a}$ for migration (diffusion) of more mobile component (interstitial) and the pre-exponential factor $A=N_{0} R D_{0} / \beta$, where $N_{0}$ is initial defect concentration and $\beta$ heating rate. 
Assuming standard parameters $N_{0}=$ $10^{17} \mathrm{~cm}^{-3}, R=10 \AA, D_{0}=10^{-3} \mathrm{~cm}^{2} \mathrm{~s}^{-1}$ (typical estimate for solid state diffusion), $\beta=10$ $\mathrm{K} / \mathrm{min}$, one gets the estimate $A=10^{8} \mathrm{~K}^{-1}$ (normal solid state diffusion). First results of this theory were discussed for the neutron irradiated sapphire. ${ }^{19}$ The analysis has demonstrated that the diffusion energy of oxygen interstitials varied considerably from one experiment to another, very likely due to different radiation fluences. To led more light to the problem, in this paper we analyze available experimental data of $F$-type center annealing in three above-mentioned materials $-\mathrm{Al}_{2} \mathrm{O}_{3}$, $\mathrm{MgO}$ and $\mathrm{MgF}_{2}$ irradiated by electrons, neutrons and heavy ions with very different fluences (and respectively, defect concentrations). As mentioned, these three materials represent a wide class of radiation resistant solids and have quite different crystalline structure and chemical bonding: $\mathrm{MgO}$ is cubic and ionic, $\mathrm{MgF}_{2}$ has rutile structure and ionic, sapphire $\left(\alpha-\mathrm{Al}_{2} \mathrm{O}_{3}\right)$ has hexagonal structure and partly covalent.

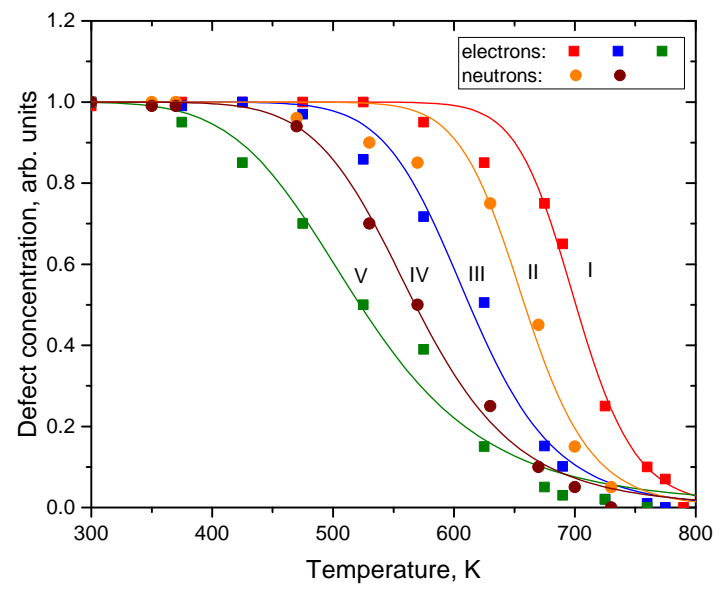

Figure 3: The kinetics of the $F^{+}$center annealing in $\mathrm{MgF}_{2}$ for different types of radiation (see Table 3 for details).

\section{Results}

We demonstrate in this paper that the first recent observation for neutron irradiated sapphire $^{19}$ could be a quite general phenomenon: diffusion of interstitial ions in many heavily irradiated ionic materials depends strongly on the radiation fluence and is characterized by unusually high mobility and low migration barriers.

The experimental kinetics of the $F$ - and $F^{+}$ center annealing in neutron irradiated sapphire obtained in several studies and their theoretical analysis described in refs. ${ }^{19,20}$ are presented in Fig. 1 and Table 1. One can see a trend in decrease of both the migration energy and preexponential $A$ with fluence (defect concentration). Note that the $F$ - and $F^{+}$centers show very similar annealing energies. The migration energy of $0.8-0.9 \mathrm{eV}$ obtained at low fluences is close to the calculated activation energy for charged oxygen interstitials ${ }^{22}$ (to be published). The relevant pre-factor is the largest and close to above-mentioned theoretical limit for a perfect solid.

Similar data for $\mathrm{MgO}$ crystals irradiated with electrons, neutrons and heavy swift ions are presented in Fig.2 and Table 2. Table 2 shows the same trend in the decrease of the migration energy and pre-factor $A$ with the fluence, irrespective the type of radiation. The largest migration energy of $1.7 \mathrm{eV}$ is close to theoretical calculations $\left(1.5 \mathrm{eV}\right.$, ref. $\left.{ }^{23}\right)$.

Lastly, Fig. 3 and Table 3 present similar results for $\mathrm{MgF}_{2}$ crystals. The annealing kinetics for the $F$ centers in $\mathrm{MgF}_{2}$ monitored by means of the two different methods - optical absorption and EPR - under electron irradiation and neutrons ${ }^{24}$ is presented in Fig. 3, respectively. All data agree very well each with other, indicating that the effect is not restricuted by a particular irradiation type. This is also not result of the increase of initial defect concentration with dose (with longer irradiation or large local concentration in narrow incident particle tracks): this would lead to increase of $N_{0}$ and thus parameter $A$, which in fact, decreases with dose by orders of magnitude.

As was mentioned above, in a crystalline structure the pre-factor is expected to be of the order of $A=10^{8}-10^{9} \mathrm{~K}^{-1}$. This is indeed close to values obtained for the lowest radiation doses (curve I in Fig.3). The relevant migration energy of $1.6 \mathrm{eV}$ corresponds to the intersti- 
Table 1: The explanation of curves I-IV in Fig.1 and the obtained migration energy of interstitial ions $E_{a}$ and pre-exponential factor $A$ in sapphire under different condition of radiation and different doses (Nr.1-10). The information is ordered with respect to the activation energy increase

\begin{tabular}{|c|c|c|c|c|}
\hline Nr. & Type & $E_{a}(\mathrm{eV})$ & $A\left(\mathrm{~K}^{-1}\right)$ & Legend \\
\hline $1(\mathrm{I})$ & $F^{+}$ & 0.89 & $7.0 \cdot 10^{1}$ & Neutron fluence $2 \cdot 10^{17} \mathrm{n} / \mathrm{cm}^{2}$, Ref. ${ }^{36}$ \\
\hline 2 & $F$ & 0.79 & $2.1 \cdot 10^{1}$ & Same as 1, Ref. ${ }^{36}$ \\
\hline $3(\mathrm{II})$ & $F^{+}$ & 0.47 & $1.2 \cdot 10^{0}$ & $\begin{array}{l}\text { Fast neutron }(\text { En }>1.2 \mathrm{MeV}) \text {, fluence } 9.1 \cdot \\
10^{17} \mathrm{n} / \mathrm{cm}^{2} \text {, Ref. }{ }^{37}\end{array}$ \\
\hline 4 & $F^{+}$ & 0.40 & $2.3 \cdot 10^{-1}$ & Fluences from $5 \cdot 10^{18}$ to $2 \cdot 10^{21} \mathrm{n} / \mathrm{cm}^{2}$, Ref. ${ }^{38}$ \\
\hline 5 & $F^{+}$ & 0.39 & $5.3 \cdot 10^{-1}$ & Fast neutron, fluence $>10^{17} \mathrm{n} / \mathrm{cm}^{2}$, Ref. ${ }^{39}$ \\
\hline 6 & $F^{+}$ & 0.35 & $1.4 \cdot 10^{0}$ & $\begin{array}{l}\text { Isochronal thermal anneal of } F \text { band in } \\
\mathrm{Al}_{2} \mathrm{O}_{3} \text { : fission-spectrum neutrons, Ref. }{ }^{40}\end{array}$ \\
\hline $7(\mathrm{IV})$ & $F^{+}$ & 0.27 & $4.0 \cdot 10^{-1}$ & $\begin{array}{l}\text { 14-MeV and fission-neutrons, fluence of } 10^{17} \\
\mathrm{n} / \mathrm{cm}^{2} \text {, Ref. }\end{array}$ \\
\hline 8 (III) & $F$ & 0.22 & $3.3 \cdot 10^{-2}$ & Same as 7, Ref. $^{41}$ \\
\hline 9 & $F$ & 0.17 & $1.3 \cdot 10^{-2}$ & Fast neutron, fluence $4 \cdot 10^{16} \mathrm{n} / \mathrm{cm}^{2}$, Ref. ${ }^{39}$ \\
\hline 10 & $F$ & 0.14 & $1.9 \cdot 10^{-3}$ & $\begin{array}{l}\text { Fast neutron }(\text { En }>1.2 \mathrm{MeV}), \text { fluence } 4 \cdot 10^{16} \\
\mathrm{n} / \mathrm{cm}^{2}, \text { Ref. }{ }^{2}\end{array}$ \\
\hline
\end{tabular}

tials in almost perfect $\mathrm{MgF}_{2}$ crystals. However, there are strong arguments ${ }^{25,26}$ that indicates that fluoride interstitials in $\mathrm{MgF}_{2}$ form neutral immobile $\mathrm{F}_{2}$ molecules and the observed energy energy could be related not entirely to the migration of a single interstitial but includes also the energy necessary to break a bond and to release it.

Measurements 2, 4, 7 (Table 3) performed on the same sample allow us to estimate dependence of the migration energy on the fluence. The insert in Graphical TOC Entry shows the exponential dependence $E_{a}(d)=$ $E_{a}(0) \exp \left(-d / d_{0}\right)$, where $d$ is dose. The fitting gives $E a(0)=1.75 \mathrm{eV}$ and $d_{0}=1.25 \cdot 10^{17}$ $\mathrm{e} / \mathrm{cm}^{2}$. This energy is close to our estimate above for the limit of low doses, as well as theoretical calculations. ${ }^{14,23}$ As the fluence increases, the migration energy strives asymptotically to zero.

The above observed correlation of the migration energy $E_{a}$ and pre-factor $A$ (Tables 1-3) fits quite well to the relation known as the MeyerNeldel rule: ${ }^{28,29}$

$$
\ln (A)=\ln \left(A_{0}\right)+E_{a} / k_{B} T_{0},
$$

where $A_{0}$ is a constant and $T_{0}$ some characteristic temperature. Eq.(1) shows how reduction of the activation energy with growing disorder is compensated by orders of magnitude decrease of the pre-factor $A$. Fig.4 demonstrates that this relation indeed is well satisfied for all three materials, and more importantly, for different types of irradiations (and initial defect spatial distributions). Note that all experimental points lie below the characteristic temperature $T_{0}$. Eq.(1) could be also interpreted as the diffusion coefficient with exponentially dependent pre-exponent

$$
D \propto \exp \left(E_{a} / k_{B} T_{0}-E_{a} / k_{B} T\right), T<T_{0} .
$$

The decrease of both the migration energy and pre-exponential $A$ with radiation fluence (defect concentration) is very well documented for the $\mathrm{MgF}_{2}$ case discussed above where experiments were performed on the same samples. In the case of sapphire this effects is partly hidden by use of different samples with different history, pre-existing defects and irradiation by neutrons of different energies and at different temperatures. It would be of great interest to perform focused experiments on the same 
Table 2: The explanation of curves I-V in Fig.2 and the obtained migration energy of interstitial ions $E_{a}$ and pre-exponential factor $A$ in $\mathrm{MgO}$ under different types of radiation and different doses (Nr.1-12)

\begin{tabular}{|c|c|c|c|c|}
\hline Nr. & Type & $E_{a}(\mathrm{eV})$ & $A\left(\mathrm{~K}^{-1}\right)$ & Legend \\
\hline 1 & ion & 1.74 & $1.4 \cdot 10^{5}$ & $\begin{array}{l}\text { Fluence } 5 \cdot 10^{14} \mathrm{Kr}^{+} / \mathrm{cm}^{2} \text { with energy } 150 \\
\text { keV, Ref. } 43\end{array}$ \\
\hline $2(\mathrm{I})$ & ion & 1.28 & $1.3 \cdot 10^{3}$ & Fluence $1 \cdot 10^{15} \mathrm{Kr}^{+} / \mathrm{cm}^{2}$, Ref. ${ }^{43}$ \\
\hline 3 & ion & 0.86 & $5.4 \cdot 10^{0}$ & $\begin{array}{l}\text { Fluence } 1 \cdot 10^{15} \mathrm{Ar}^{+} / \mathrm{cm}^{2} \text { with energy } 100 \\
\text { keV, Ref. } 44\end{array}$ \\
\hline 4 & electron & 0.71 & $1.5 \cdot 10^{2}$ & $1.7 \mathrm{MeV}, F$ centers $1.6 \cdot 10^{18} \mathrm{~cm}^{-3}$, Ref. ${ }^{45}$ \\
\hline $5(\mathrm{III})$ & electron & 0.68 & $1.1 \cdot 10^{1}$ & $\begin{array}{l}\text { Optical absorption, } 1.8 \mathrm{MeV} \text {, fluence similar } \\
\text { to } 8 \cdot 10^{19} \mathrm{n} / \mathrm{cm}^{2} \text {, Ref. }{ }^{47}\end{array}$ \\
\hline 6 & electron & 0.65 & $1.5 \cdot 10^{2}$ & $\begin{array}{l}\text { Optical absorption, } 3 \mathrm{MeV}, F \text { centers } 5 \cdot 10^{18} \\
\mathrm{~cm}^{-3} \text {, Ref. }{ }^{46}\end{array}$ \\
\hline $7(\mathrm{II})$ & ion & 0.60 & $6.0 \cdot 10^{-1}$ & $\begin{array}{l}\text { Fluence } 5 \cdot 10^{15} \mathrm{Kr}^{+} / \mathrm{cm}^{2} \text { with energy } 150 \\
\text { keV, Ref. }\end{array}$ \\
\hline 8 & neutron & 0.54 & $1.0 \cdot 10^{1}$ & Fluence $1 \cdot 10^{17} \mathrm{n} / \mathrm{cm}^{2}$, Ref. $^{48}$ \\
\hline 9 & ion & 0.41 & $1.7 \cdot 10^{-2}$ & Same as 3, Ref. ${ }^{44}$ \\
\hline 10 & ion & 0.39 & $2.2 \cdot 10^{-2}$ & Same as 3 , Ref. ${ }^{44}$ \\
\hline 11 & Ne ions & 0.24 & $2.5 \cdot 10^{-3}$ & Fluence $1 \cdot 10^{15} \mathrm{Ne} / \mathrm{cm}^{2}$, Ref. $^{49}$ \\
\hline 12 (IV) & neutron & 0.23 & $3.6 \cdot 10^{-2}$ & $\begin{array}{l}\text { Fluence } 6 \cdot 10^{17} \mathrm{n} / \mathrm{cm}^{2} \text { with energy }>1 \mathrm{MeV} \text {, } \\
\text { Ref. }\end{array}$ \\
\hline
\end{tabular}

Table 3: The explanation of curves I-V in Fig.3 and the obtained migration energy of interstitial ions $E_{a}$ and pre-exponential factor $A$ in $\mathbf{M g F}_{2}$ under different types of radiation and different doses $(\mathrm{Nr} .1-7)$

\begin{tabular}{|c|c|c|c|c|}
\hline Nr. & Type & $E_{a}(\mathrm{eV})$ & $A\left(\mathrm{~K}^{-1}\right)$ & Legend \\
\hline 1 & electron & 1.87 & $4.8 \cdot 10^{10}$ & $\begin{array}{l}\text { Optical absorption, } 2 \mathrm{MeV} \text { electron irradia- } \\
\text { tion, dose } 1 \cdot 10^{16} \mathrm{e} / \mathrm{cm}^{2} \text {, Ref. }{ }^{24}\end{array}$ \\
\hline $2(\mathrm{I})$ & electron & 1.60 & $1.0 \cdot 10^{8}$ & $\begin{array}{l}\text { EPR, } 2 \mathrm{MeV} \text { electron irradiation, dose } 1 \cdot 10^{16} \\
\text { e/ } \mathrm{cm}^{2}, \text { Ref. }^{24}\end{array}$ \\
\hline $3(\mathrm{II})$ & neutron & 1.24 & $9.8 \cdot 10^{6}$ & $\begin{array}{l}\text { EPR, E }>1 \mathrm{MeV} \text {, irradiation } 15 \mathrm{~min} \text {, flux } \\
3 \cdot 10^{13} \mathrm{n} / \mathrm{cm}^{2} \mathrm{~s} \text {, Ref. }{ }^{24}\end{array}$ \\
\hline 4 (III) & electron & 0.80 & $8.4 \cdot 10^{3}$ & $\begin{array}{l}\text { EPR, } 2 \mathrm{MeV} \text { electron irradiation, dose } 1 \cdot 10^{17} \\
\text { e/ } \mathrm{cm}^{2}, \text { Ref. }^{24}\end{array}$ \\
\hline $5(\mathrm{IV})$ & neutron & 0.56 & $1.8 \cdot 10^{2}$ & $\begin{array}{l}\text { EPR, E > } 1 \mathrm{MeV} \text {, irradiation } 10 \mathrm{~h} \text {, flux } 3 \cdot \\
10^{13} \mathrm{n} / \mathrm{cm}^{2} \mathrm{~s} \text {, Ref. }{ }^{24}\end{array}$ \\
\hline 6 & ions & 0.46 & $9.6 \cdot 10^{0}$ & $\begin{array}{l}\text { Optical absorption, U ions }(11.1 \mathrm{MeV} / \mathrm{u}) \text {, } \\
\text { fluence } 6 \cdot 10^{11} \mathrm{~cm}^{-2} \text {, Ref. }{ }^{50}\end{array}$ \\
\hline 7 & electron & 0.35 & $3.5 \cdot 10^{0}$ & $\begin{array}{l}\text { EPR, } 2 \mathrm{MeV} \text { electron irradiation, dose } 2 \cdot 10^{17} \\
\text { e } / \mathrm{cm}^{2}, \text { Ref. }^{24}\end{array}$ \\
\hline
\end{tabular}



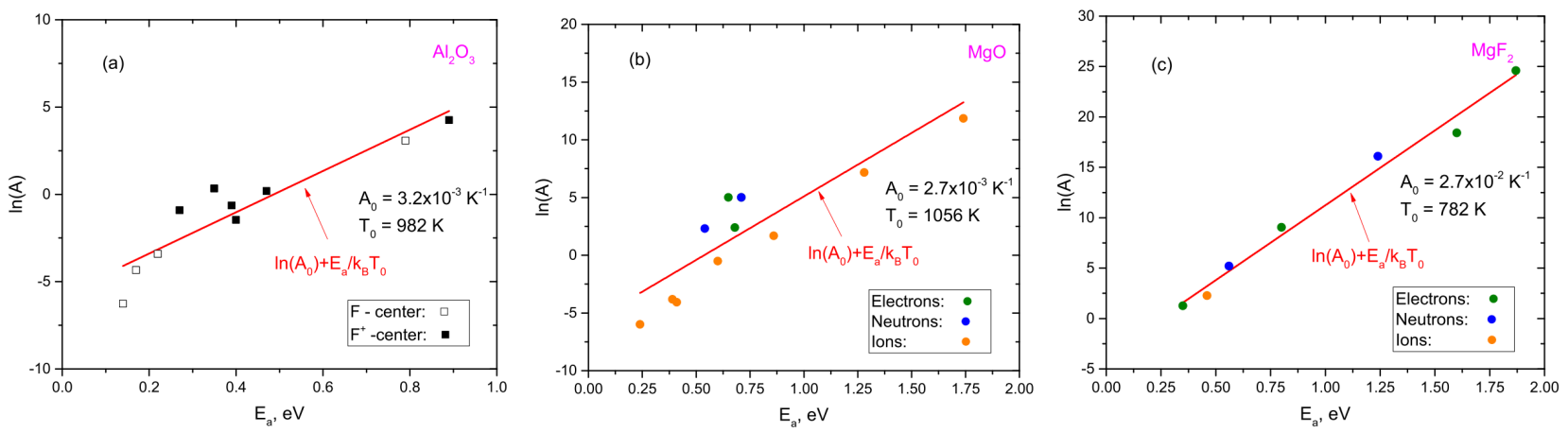

Figure 4: Correlation of the effective energies and pre-exponents for sapphire (a), $\operatorname{MgO}(\mathrm{b})$ and $\mathrm{MgF}_{2}$ (c). The high quality of this correlation is characterized by the standard Pearson correlation coefficient: (a) $r=0.92819$, (b) $r=0.87847$ and (c) $r=0.99291$, very close to the perfect case $(r=1)$. In all three cases the positive linear relationship takes place between the two variables.

sapphire samples varying only the neutron $\mathrm{flu}-$ ences, similarly as it was performed for $\mathrm{MgF}_{2} \cdot{ }^{24}$

\section{Discussion and Conclusions}

Summing up, it is demonstrated, for the first time, that in three types of strongly irradiated ionic solids of different crystalline structure and chemical nature, the pre-exponential factor of diffusion is strongly correlated with the migration energy. In other words, the defect recombination kinetics is not characterized uniquely by the activation energy for diffusion with a constant pre-exponent (as generally accepted in solid state physics and chemistry) but instead these parameters depend on the radiation fluence which considerably complicates analysis of the radiation-induced kinetic processes. Note that this correlation $\left(E_{a}-A\right)$ effect, known as the Meyer-Neldel rule, ${ }^{28}$ is well known in chemistry, biology, even semi-conductor physics. ${ }^{29-32}$ The foundations of this empirical rule are still not fully understood. One of possible phenomenological models ${ }^{33}$ claims that eq.(1) holds in disordered systems with exponential probability distribution of energy barriers of localized quasi-particles. The relation (1) is observed usually in multicomponent systems (for example, metallurgical slags ${ }^{34}$ containing tens of oxides). Our observation shows that this is possible in simple systems and without changes of composition. Sim- ilar observations were also done in glasses under weak neutron or ion irradiation characterized by small variation of activation energies: chalcogenide glass ${ }^{35}$ and metallic glass. ${ }^{30}$

One of possible logical explanations of the observed effect could be a growing disordering of materials under irradiation with a continuous transition from a perfect crystalline structure to the amorphous-like one. ${ }^{27}$ However, three studied materials do not reveal considerable amorphization and strong disordering under irradiation. ${ }^{51}$ Moreover, experiments ${ }^{52}$ show that oxygen diffusion in vitrous silica (and probably, many other disorder solids) is slower than in the crystalline phase, whereas computer modeling of a series of binary oxides ${ }^{51}$ indicated that activation barriers for radiation damage recovery increses with the material disordering. Another explanation could be related with the simulations of the radiation damage of $\mathrm{MgO}^{53}$ which suggested extremely high mobility of small interstitial clusters (and thus, average interstitial mobility). A number of such clusters could increase with the fluence growth and explain our observation. More detailed experimental and theoretical studies for a broader class of materials are necessary for the understanding the observed effect.

Acknowledgement The authors thanks A. Ch. Lushchik, M. Izerrouken and V. Lisitsyn for stimulating discussions. This work has been carried out within the framework 
of the EUROfusion Consortium and has received funding from the Euroatom research and training programme 2014-2018 under grant agreement No 633053. The views and opinions expressed herein do not necessarily reflect those of the European Commission. R.V. acknowledges the financial support by the MEIC (Ministerio de Economa, Industria y Competitivad) (Project ENE2015-70300-C3-1-R). The calculations were performed using facilities of the Stuttgart Supercomputer Center (project DEFTD 12939).

\section{References}

(1) Tracy, C. L., Lang, M., Pray, J. M., Zhang, F., Popov, D., Park, C., Trautmann, C.; Bender, M.; Severin, D.; Skuratov, V.A.; Ewing, R. C. Redox response of actinide materials to highly ionizing radiation. Nature Communications 2015, 6, 6133.

(2) Grimes, R. W.; Konings, R. J. M.; Edwards, L. Greater tolerance for nuclear materials. Nature Materials 2008, 7, 683685 .

(3) Uberuaga, B.P.; Tang, M.; Jiang, C.; Valdez, J.A.; Smith, R.; Wang, Y.; Sickafus, K.E. Opposite correlations between cation disordering and amorphization resistance in spinels versus pyrochlores. $\mathrm{Na}$ ture Communications 2015, 6, 8750.

(4) Mota, F.; Ortiz, C.J.; Vila, R.; Casal, N.; Garcia, A.; Ibarra, A. Calculation of damage function of $\mathrm{Al}_{2} \mathrm{O}_{3}$ in irradiation facilities for fusion reactor applications. $J$. Nucl. Mater. 2013, 442 (Suppl. 1), 56995704 .

(5) DeSalvo, R.; Said, A.; Hagan, D.J.; Van Stryland, E.W.; Sheik-Bahae, M. Infrared to ultraviolet measurements of two-photon absorption in wide bandgap solids. IEEE. J. Quantum Electr. 1996, 32, 1324-1333.

(6) Kotomin, E.A.; Kuzovkov, V.N. Phenomenological kinetics of Frenkel defect recombination and accumulation in ionic solids. Rep. Prog. Phys. 1992, 55, 20792188 .

(7) Kotomin, E.A.; Kuzovkov, V.N. Modern Aspects of Diffusion-Controlled Reactions; series of Comprehensive Chemical Kinetics; Elsevier: Amsterdam, 1996; Vol. 34.

(8) Kuzovkov, V.N.; Kotomin, E.A.; Olvera de la Cruz, M. The non-equilibrium charge screening effects in diffusion-driven systems with pattern formation. J. Chem. Phys. 2011, 135, 034702.

(9) Kuzovkov, V.N.; Zvejnieks, G.; Kotomin, E.A. Theory of non-equilibrium critical phenomena in three-dimensional condensed systems of charged mobile nanoparticles. Phys. Chem. Chem. Phys. 2014, 16, 13974-13983.

(10) Xu, W.; Zhang, Y.; Cheng G.; Jian W.; Millett, P.C.; Koch, C.C.; Mathaudhu, S.N.; Zhu, Y. In-situ atomic-scale observation of irradiation-induced void formation. Nature Communications 2013, 4, 2288

(11) Sickafus, K. E.; Minervini, L.; Grimes, R. W.; Valdez, J. A.; Ishimaru, M.; Li, F.; McClellan, K. J.; Hartmann, T. Radiation tolerance of complex oxides. Science $\mathbf{2 0 0 0 ,}$ 289, 748751.

(12) Itoh, N.; Stoneham, A.M. Material Modification by Electronic Excitations; Cambridge: Cambridge University press, 2000.

(13) Kotomin, E.A.; Popov, A.I. Radiationinduced point defects in simple oxides. Nucl. Instr. Meth. Phys. Res. B 1998, 141, 1-15.

(14) Popov, A.I.; Kotomin, E.A.; Kuklja M.M. Quantum chemical calculations of the electronic center diffusion in $\mathrm{MgO}$ crystals. Phys. Stat. Sol. (b) 1996 195, 61-66.

(15) Frenkel, Y.I. Kinetic Theory of Liquids; Oxford: Clarendon Press, 1946. 
(16) Faber, T.E. An Introduction to the Theory of Liquid Metals; Cambridge: Cambridge University Press, 1972.

(17) Lushchik, A.; Lushchik, Ch.; Schwartz, K.; Vasil'chenko, E.; Kärner, T.; Kudryavtseva, I.; Issakhanyan, V.; Shugai, A. Stabilization and annealing of interstitials formed by radiation in binary metal oxides and fluorides. Nucl. Instrum. Meth. Phys. Res. B 2008, 266, 2868-2871.

(18) Kuzovkov, V.N.; Popov, A.I.; Kotomin, E.A.; Monge, M.A.; González, R.; Chen, $\mathrm{Y}$. The kinetics of $F$-center aggregation in thermochemically reduced $\mathrm{MgO}$ single crystals. Phys. Rev. B 2001, 64, 064102.

(19) Kotomin, E.A.; Kuzovkov, V.N.; Popov, A.I.; Vila, R. Kinetics of $F$ center annealing and colloid formation in $\mathrm{Al}_{2} \mathrm{O}_{3}$. Nucl. Instr. Meth. Phys. Res. B 2016, 374, 107110.

(20) Kuzovkov, V.N.; Popov, A.I.; Kotomin, E.A.; Moskina, A.M.; Vasil'chenko, E.; Lushchik, A. Theoretical analysis of the kinetics of low-temperature defect recombination in alkali halide crystals. Low Temp. Phys. 2016, 42, 748-755.

(21) Smoluchowski, M.V. Versuch einer mathematischen Theorie der Koagulationskinetik kolloider Lösungen. Z. Phys. Chem. B 1917, 92 129-168.

(22) Platonenko, A.; Gryaznov, D.; Zhukovskii, Yu.F.; Kotomin, E.A. Ab initio simulations on charged interstitial oxygen migration in corundum. Nucl. Instrum. Meth. Phys. Res. B 2017, in press

(23) Brudevoll, T.; Kotomin, E.A.; Christensen, N.E. Interstitial-oxygen atom diffusion in MgO. Phys. Rev. B 1996, 53, 7731-7735.

(24) Kolopus, J.L.; Lewis, J.T.; Unruh, W.P.; Nelson, L.G. The F centres in $\mathrm{MgF}_{2}$. II. Optical absorption and EPR. Journal of
Physics C: Solid State Physics 1971, 4, 3007-3014.

(25) Abuova F.U.; Kotomin E.A.; Lisitsyn V.M.; Akilbekov A.T.; Piskunov, S. $\mathrm{Ab}$ initio modelling of radiation damage in $\mathrm{MgF}_{2}$ crystals. Nucl. Instrum. Meth. Phys. Res. B 2014, 326, 314-317.

(26) Lisitsyn, V.M.; Lisitsyna, L.A.; Popov, A.I.; Kotomin, E.A.; Abuova, F.U.; Akilbekov, A.T.; Maier, J. Stabilization of primary mobile radiation effects in $\mathrm{MgF}_{2}$ crystals. Nucl. Instrum. Meth. Phys. Res. B 2016, 374, 24-28.

(27) Ziman, J. M. Models of disorder : the theoretical physics of homogeneously disordered systems. Cambridge: Cambridge University Press, 1979.

(28) Meyer, W.; Neldel, H. Concerning the relationship between the energy constant epsilon and the quantum constant alpha in the conduction-temperature formula in oxydising semi conductors, Physikalische Zeitschrift 1937, 38, 1014-1019.

(29) Jones, A. G. Compensation of the MeyerNeldel Compensation Law for $\mathrm{H}$ diffusion in minerals. Geochem. Geophys. Geosyst. 2014, 15, 2616-2631.

(30) Mehta, N.; Singh, K.; Saxena, N. S. Correlation between pre-exponential factor and activation energy of non-isothermal crystallization for virgin and irradiated Fe78B13Si9 metallic glass. Physica B 2009, 404, 2184-2188.

(31) Linert, W.; Yelon, A. Isokinetic relationships preface, Monatshefte Fur Chemie, 2013, 144, 1-2.

(32) Ngai, K.L. Meyer-Neldel rule and anti Meyer-Neldel rule of ionic conductivity: Conclusions from the coupling model. Solid State Ionics 1998, 105, 231-235.

(33) Dyre, J. C. A phenomenological model for the Meyer-Neldel rule. J. Phys. C: Solid State Phys. 1986, 19, 5655-5664. 
(34) Gasik, M. M.; Gasik, M. I.; Leontev, L. I.; Dashevskii, V. Ya.; Griogorovich, K. V. Fundamental relation between the main parameters of the thermally activated transport phenomena in complex oxide melts, Russian Metallurgy (Metally) 2014, 7, 503-508.

(35) Mehta, N.; Singh, K; Saxena, N.S. Effect of slow neutron radiation on the pre-exponential factor of thermally activated crystallization in Se96In4 chalcogenide glass. J. Phys. D: Appl. Phys. 2008, 41, 135406.

(36) Ramìrez, R.; Tardìo, M.; González, R.; Munoz Santiuste, J.E.; Kokta, M.R. Optical properties of vacancies in thermochemically reduced $\mathrm{Mg}$-doped sapphire single crystals. J. Appl. Phys. 2007, 101, 123520 .

(37) Izerrouken, M.; Benyahia, T. Absorption and photoluminescence study of $\mathrm{Al}_{2} \mathrm{O}_{3}$ single crystal irradiated with fast neutrons. Nucl. Instrum. Meth. Phys. Res. B 2010, 268, 2987-2990.

(38) Vila, R.; Ibarra, A.; de Castro, M.; Clinard, F.W. Thermally stimulated depolarization currents in neutron-irradiated $\mathrm{Al}_{2} \mathrm{O}_{3}$. Solid St. Comm. 1991, 79, 295297.

(39) Atobe, K.; Ishimoto, N.; Nakagawa, M. Irradiation-induced aggregate centers in single crystal $\mathrm{Al}_{2} \mathrm{O}_{3}$. Phys. Stat. Sol. (a) 1985, 89, 155-162.

(40) Evans, B.D. A review of the optical properties of anion lattice vacancies, and electrical conduction in $\alpha-\mathrm{Al}_{2} \mathrm{O}_{3}$ : their relation to radiation-induced electrical degradation. J. Nucl. Mater. 1995, 219, 202223 (review article)

(41) Bunch, J. M.; Clinard JR, F. W. Damage of single-crystal $\mathrm{Al}_{2} \mathrm{O}_{3}$ by $14-\mathrm{MeV}$ neutrons. Journal of The American Ceramic Society 1974, 57, 279-280.
(42) Izerrouken, M.; Djouadi, Y.; Zirour, H. Annealing process of $F$ - and $F^{+}$-centers in $\mathrm{Al}_{2} \mathrm{O}_{3}$ single crystal induced by fast neutrons irradiation. Nucl. Instrum. Meth. Phys. Res. B 2014, 319, 29-33.

(43) Friedland, E. Annealing of radiation damage in $\mathrm{MgO}$ single crystals after crypton implantation. Nucl. Instrum. Meth. Phys. Res. B 1994, 85, 316-320.

(44) Usov, I.O.; Arendt, P.N.; Groves, J.R.; Stan, L.; DePaula, R.F. Annealing of radiation damage in (100), (110) and (111) $\mathrm{MgO}$ single crystals implanted with $\mathrm{Ar}^{+}$ ions. Nucl. Instrum. Meth. Phys. Res. B 2006, 243, 87-91.

(45) Chen, Y.; Williams, R. T.; Sibley, W. A. Defect cluster centers in MgO. Phys. Rev. 1969, 182, 960-964.

(46) Scholz, C.; Ehrhart, P. F-centers and oxygen interstitials in MgO. Mat. Res. Soc. Proc. 1993, 279, 427-432.

(47) De Castro, M. J.; Rivas, J.A. Stored energy in electron irradiated $\mathrm{MgO}$. Radiation effects, 1986, 97, 227-233.

(48) Kärner, T.; Dolgov, S.; Lushchik, A.; Mironova-Ulmane, N.; Nakonechnyi, S.; Vasil'chenko, E. High-temperature thermoluminescence manifestations of anion interstitials in neutron-irradiated pure and doped single crystals of $\mathrm{MgO}$. Radiation Effects and Defects in Solids 2001, 155(14), 171-175

(49) Evans, B. D. Spectral study of $\mathrm{Ne}^{+}$bombarded crystalline MgO. Phys. Rev. B 1974, 9, 5222-5235.

(50) El-Said, A.S.; Neumann, R.; Schwartz, K.; Trautmann, C. Swelling and creation of color centers in $\mathrm{MgF}_{2}$ single crystals irradiated with energetic heavy ions. $\mathrm{Nucl}$. Instrum. Meth. Phys. Res. B 2006, 245, 250-254.

(51) Trachenko, K. Understanding resistance to amorphization by radiation damage. J. 
Phys.: Condens. Matter 2004, 16, R14911515.

(52) Rodriguez-Viejo, J; Sibieude, F; Clavaguera-More, M.T.; Monty, C. ${ }^{18} \mathrm{O}$ diffusion through amorphous $\mathrm{SiO}_{2}$ and crystobalite. Appl. Phys. Lett. 1993, 63, 1906-1908.

(53) Uberuaga, B.P.; Smith, R.; Cleave, A.R; Henkelman, G; Grimes, R.W.; Voter, A.F.; Sickafus, K.E. Exploring long-time response to radiation damage in $\mathrm{MgO}$. Nucl. Instrum. Meth. Phys. Res. B 2005, 228, 260-273. 


\section{Graphical TOC Entry}

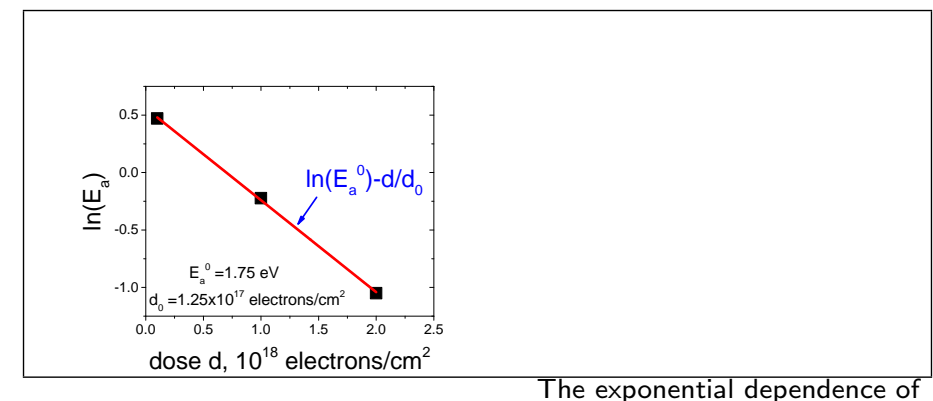

the migration energy on the radiation fluence (estimate for $\mathrm{MgF}_{2}$ ) 